\title{
GREEN TOURISM - A CONTRIBUTING FACTOR TO THE DEVELOPMENT OF THE GREEN ECONOMY
}

\section{DAVID LOLUA}

\section{Associate Professor}

European University, Georgia

lolua.d@gmail.com

\section{MANANA ALADASHVILI}

\section{Associate Professor}

European University, Georgia

manana.aladashvili@gmail.com

Abstract. The article discusses green tourism and notes that green tourism in the regions of Georgia is at an early stage of development, with the potential and desire of the local population as a major user of green services. The proposed system of indicators may be universal for express-evaluation of the state at the regional level. The existing system of green tourism has shown that the state has to change its approaches to the formation of green tourism products (lack of green certification, etc.). The study identified trends in the growth of domestic tourism flows that can be proposed as effective promotion of regional tourism. For the further successful development of green tourism, it is first and foremost necessary to educate the public on a clear understanding of the increase in the price of these tours. One must realize and be aware that the money he or she pays to achieve a high quality of tourism is to serve specific ecological measures, one must feel the result of their implementation. Directions for improving green tourism include management system, ecotourism transport support, infrastructure development and provision of a wide range of services to the population that do not harm the ecological condition of the area, enhances the general ecological culture of the population, introduces new technologies for resource consumption and for waste recycling.

KEYWORDS: GREEN TOURISM, GREEN ECONOMY, SUSTAINABLE DEVELOPMENT.

For citation: Lolua, D., Aladashvili, M. (2020). Green tourism - a contributing factor to the development of the green economy. Globalization and Business, №9, pp. 171-178 (In Georgian). https://doi.org/10.35945/gb.2020.09.021 


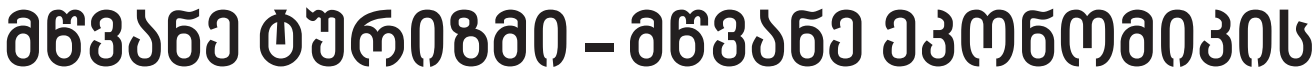

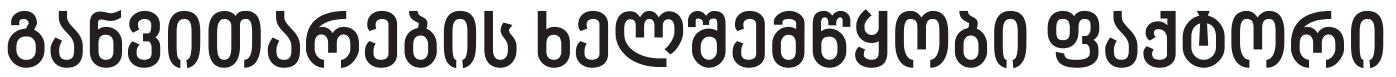

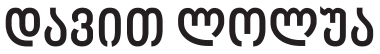

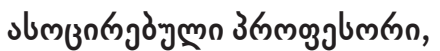

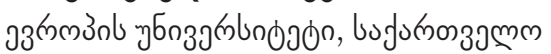

lolua.d@gmail.com

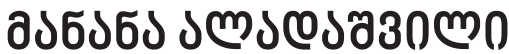

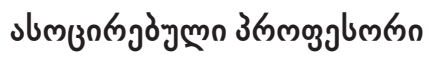

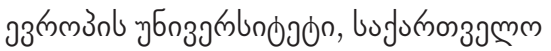

manana.aladashvili@gmail.com

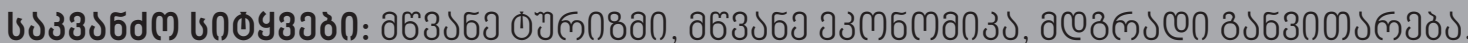

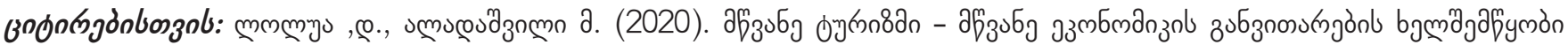

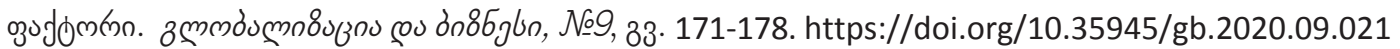

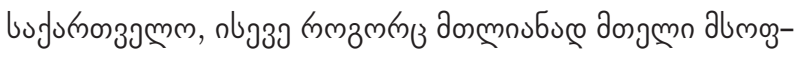

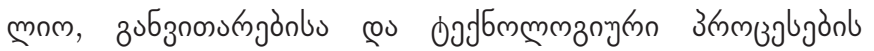

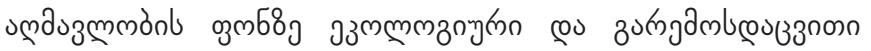

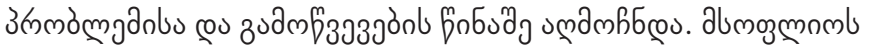

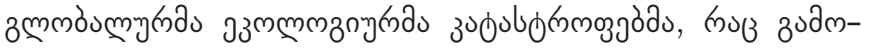

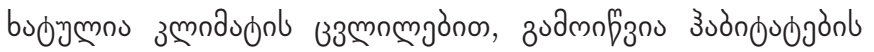

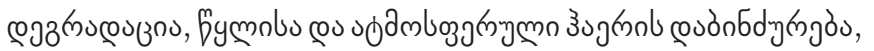

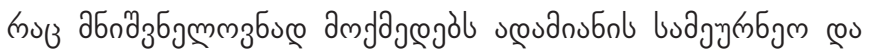

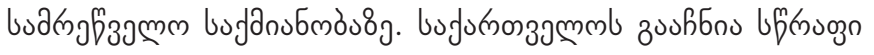

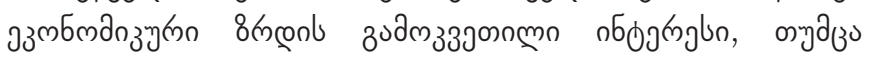

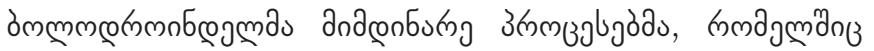

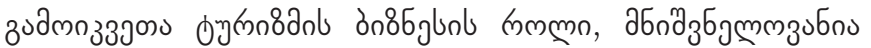

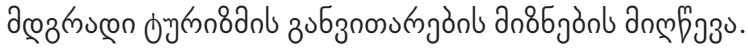

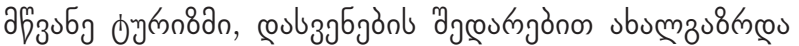

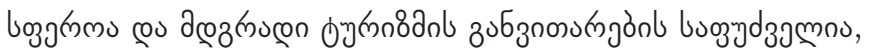

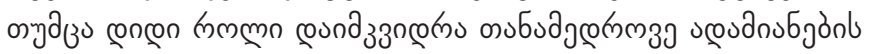

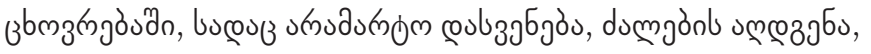

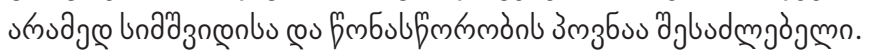

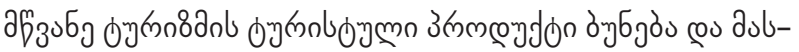

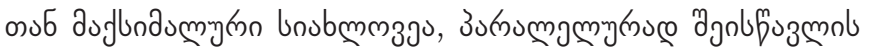

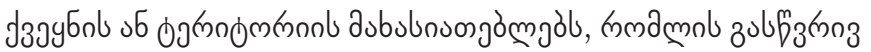

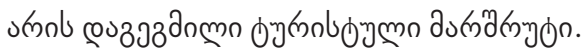

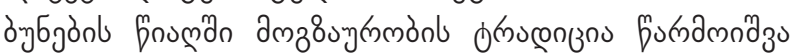

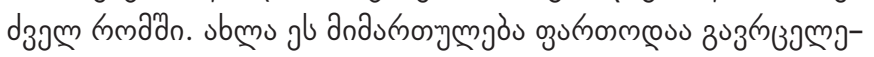

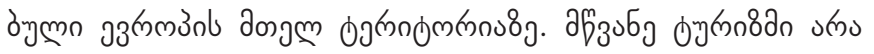

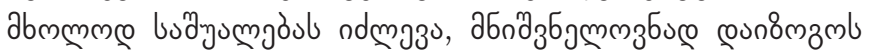

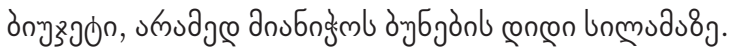

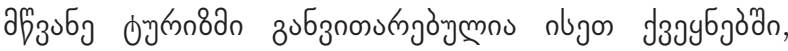

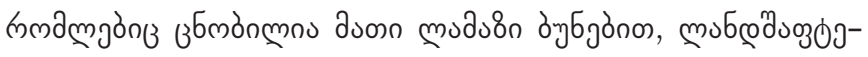

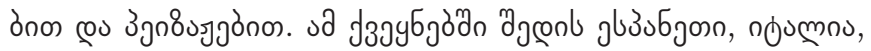

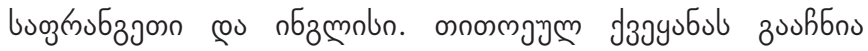

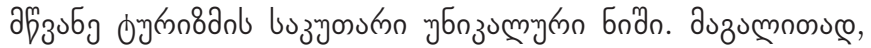

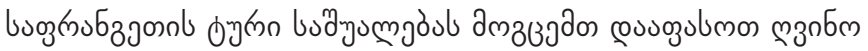

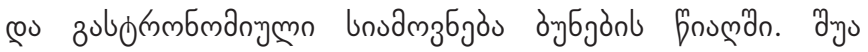

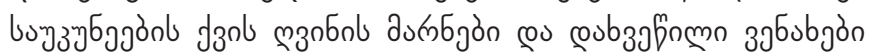

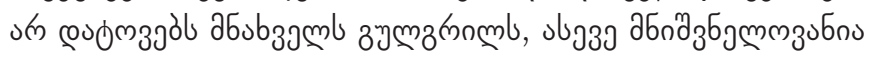

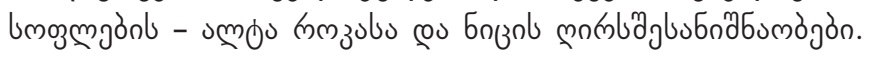

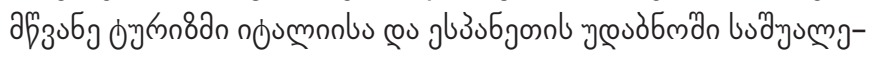

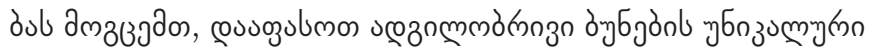

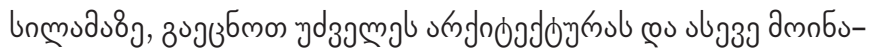

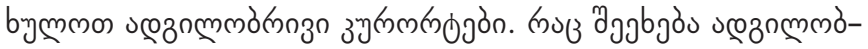

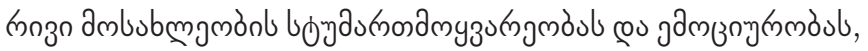

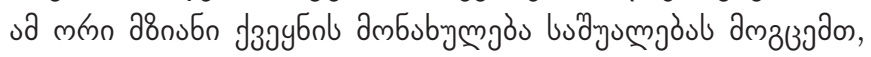

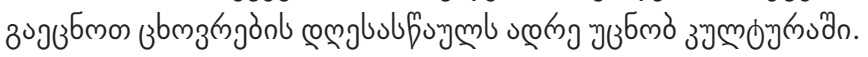

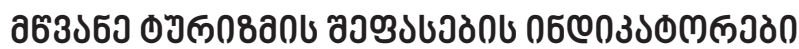

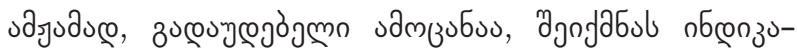

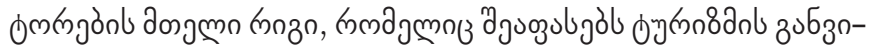

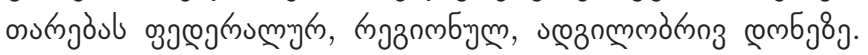

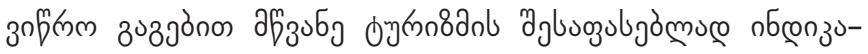

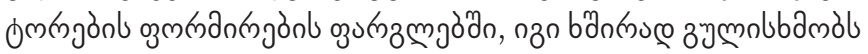

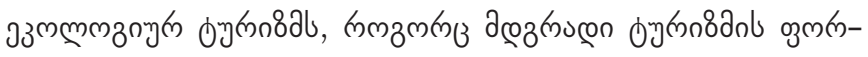

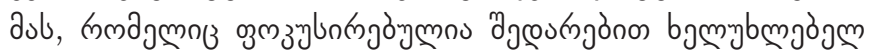

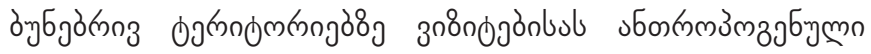
8jamjagegonl zumgag. 


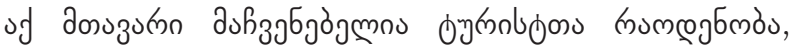

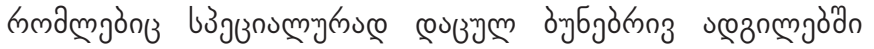

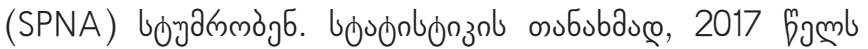

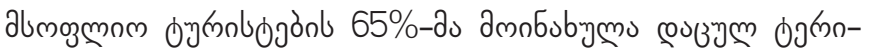
omknojòn.

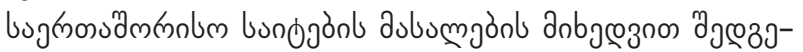

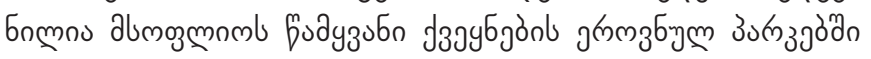

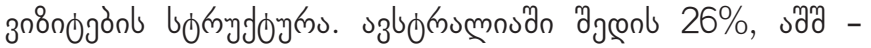

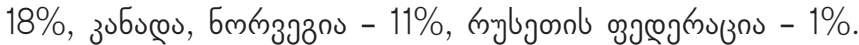

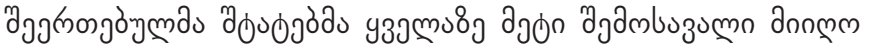

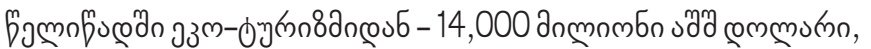

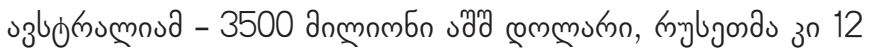

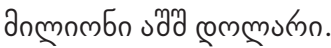

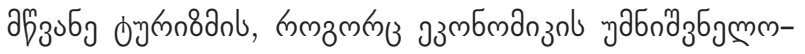

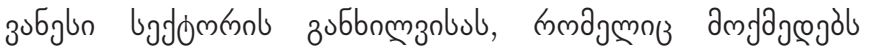

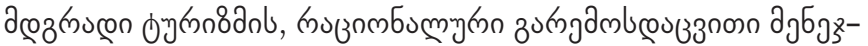

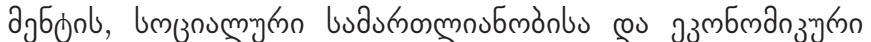

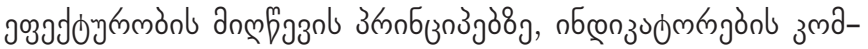

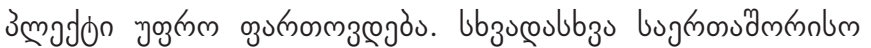

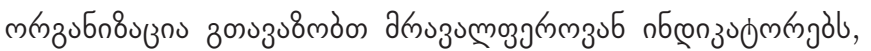

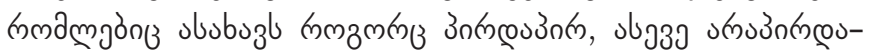

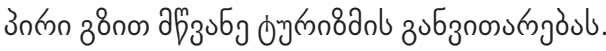

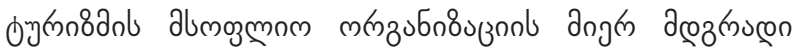

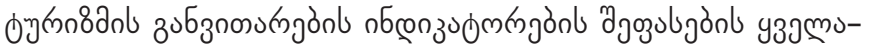

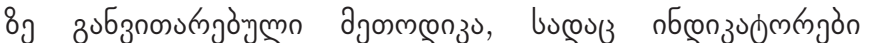

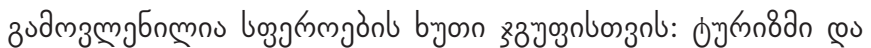

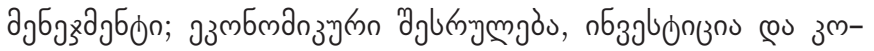

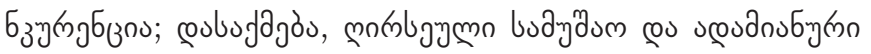

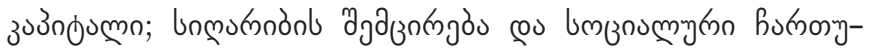

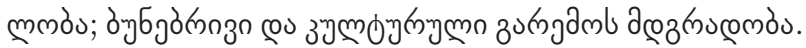

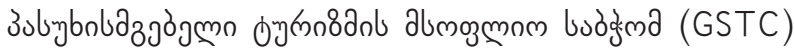

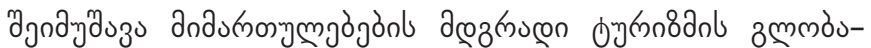

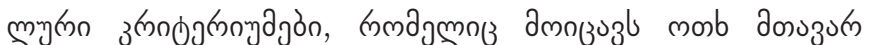

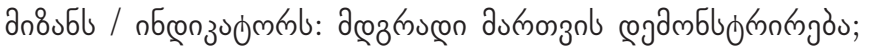

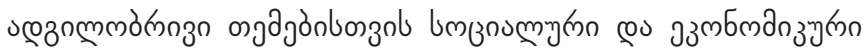

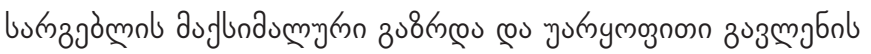

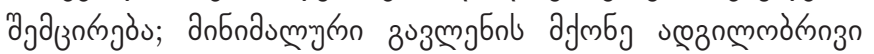

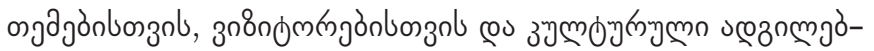

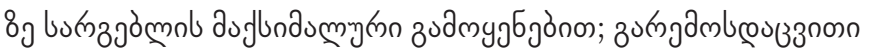

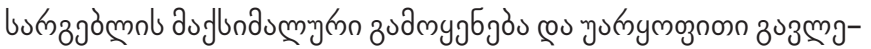

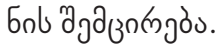

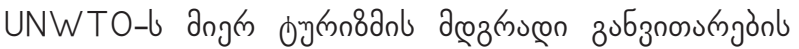

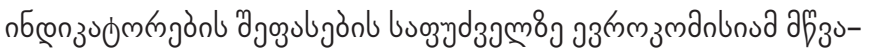

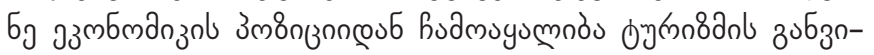

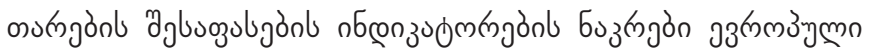

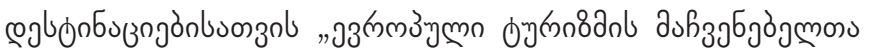

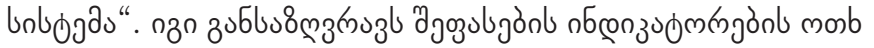
аммзз

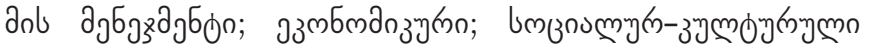

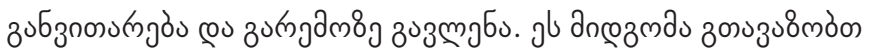

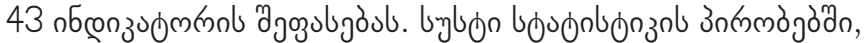

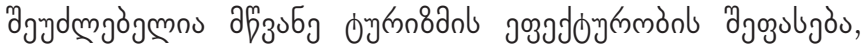

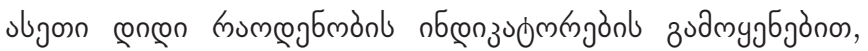

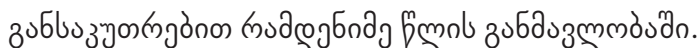

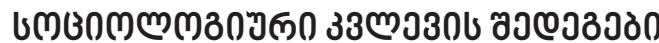

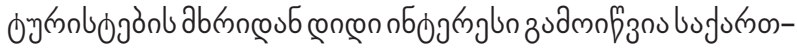

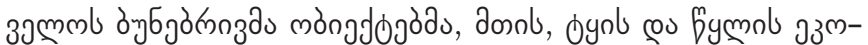

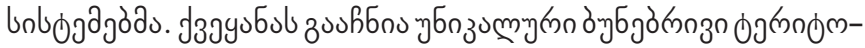

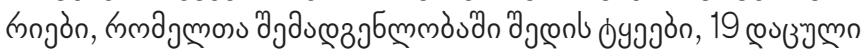

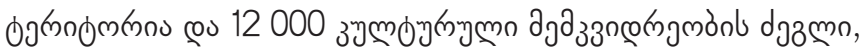

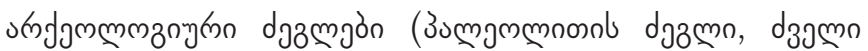

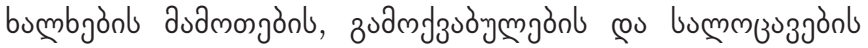

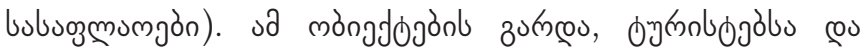

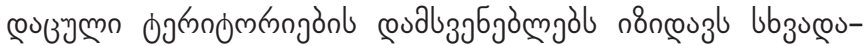

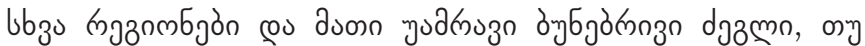

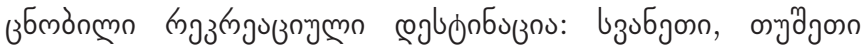

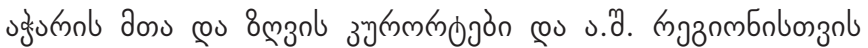

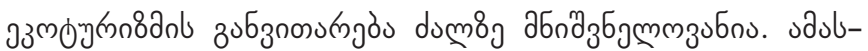

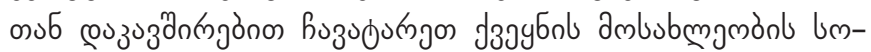

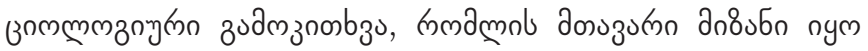

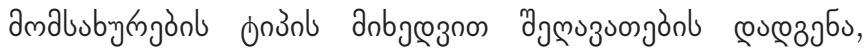
oy

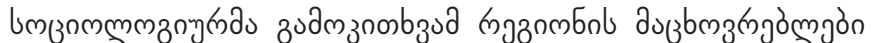

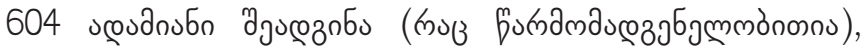

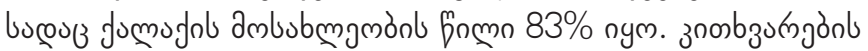

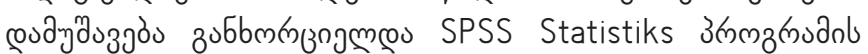

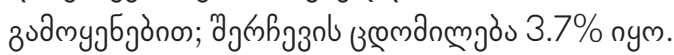

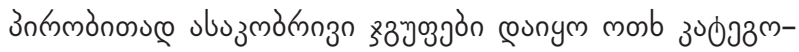

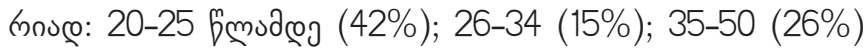

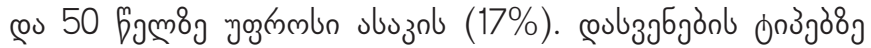

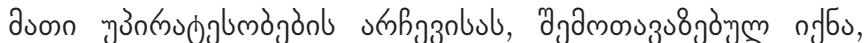

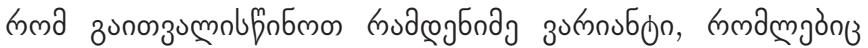

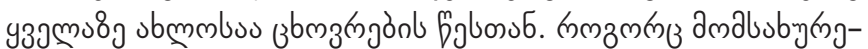

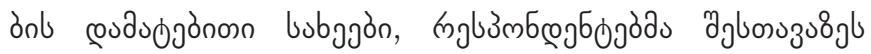

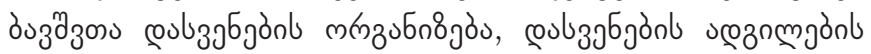

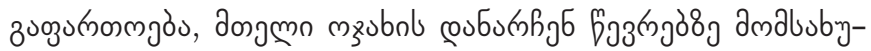

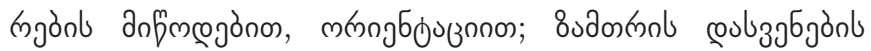

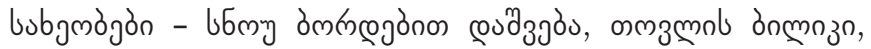

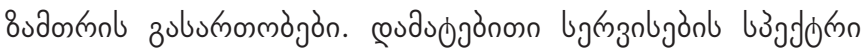

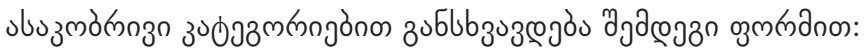

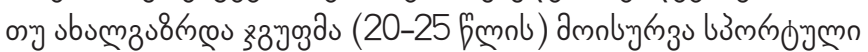

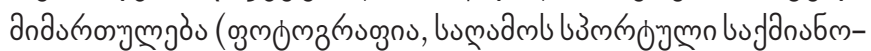
on

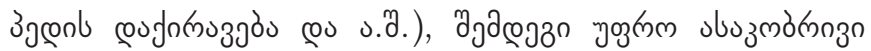

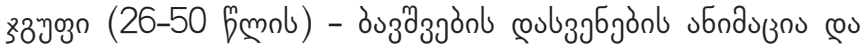

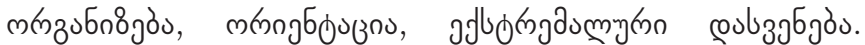

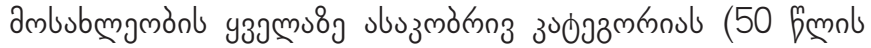

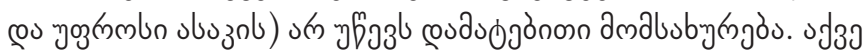




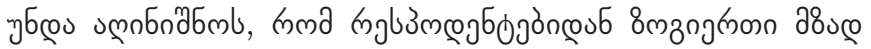

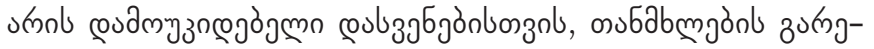

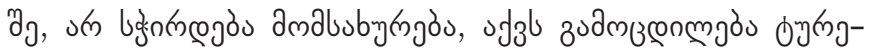

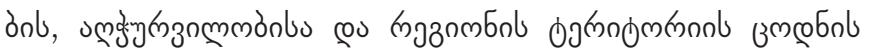

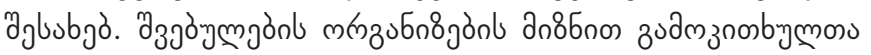

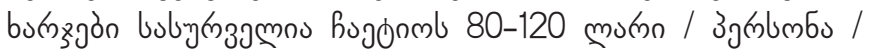

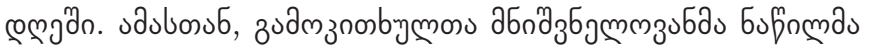

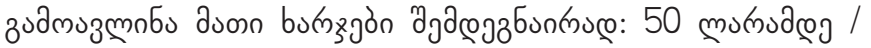

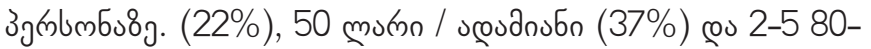
120 mumn/ uguanubn (30\%).

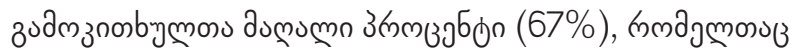

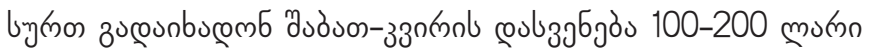

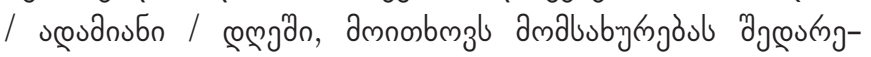

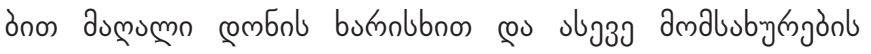

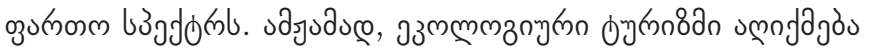

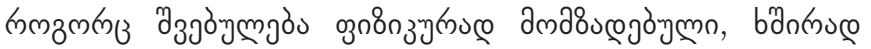

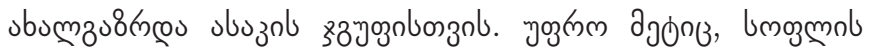

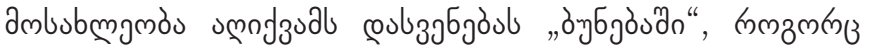

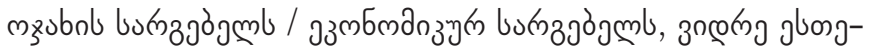

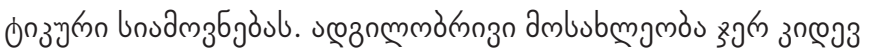

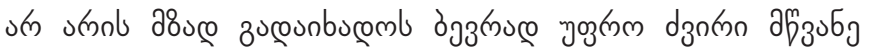

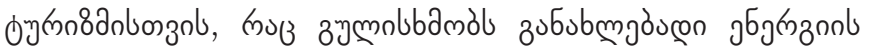

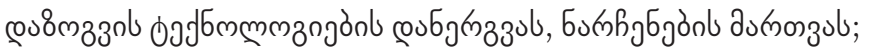

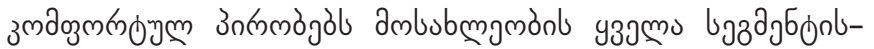

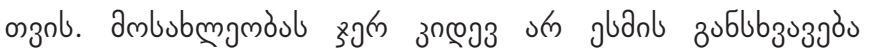

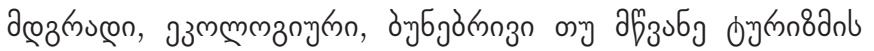

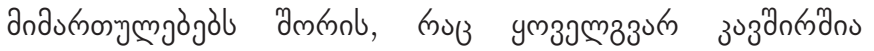

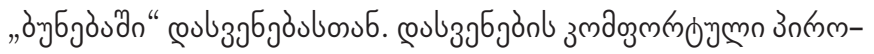

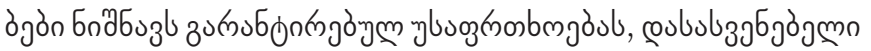
mòngdojön

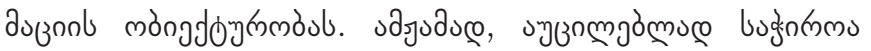
a

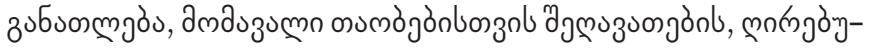

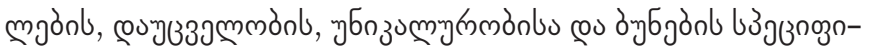

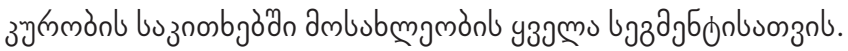

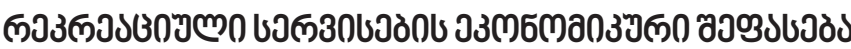

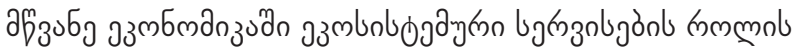

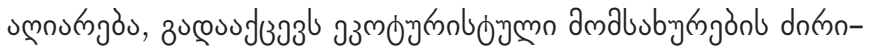

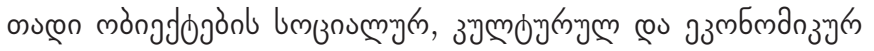

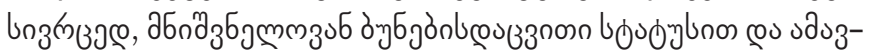

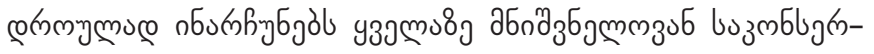

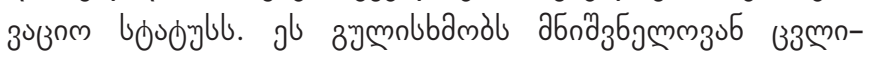

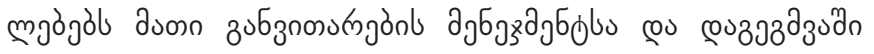

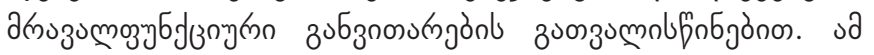

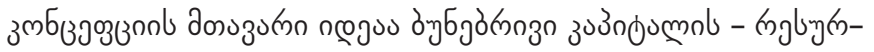

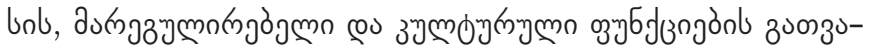

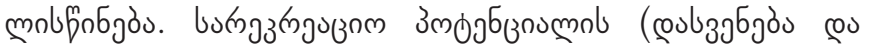

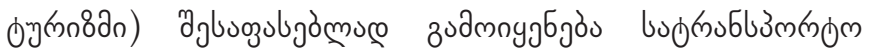

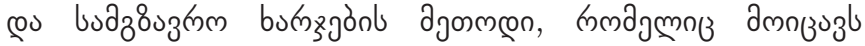

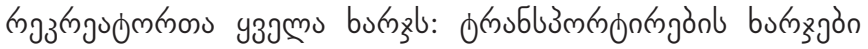
(

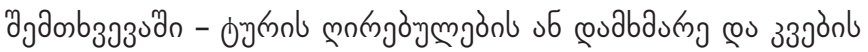

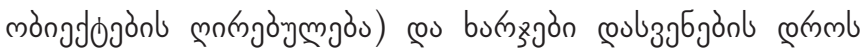

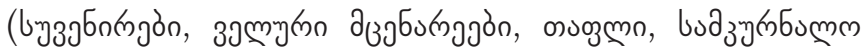

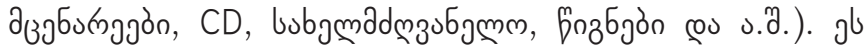

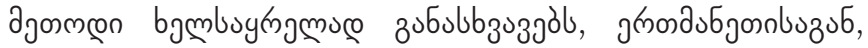

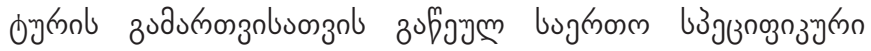

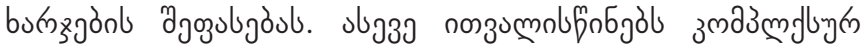

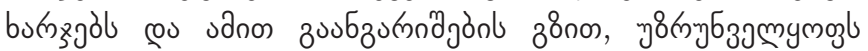

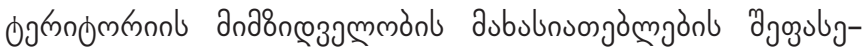

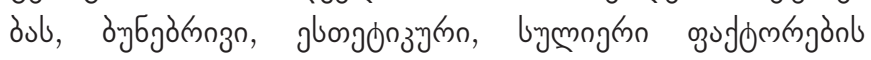

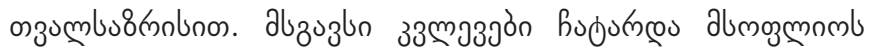

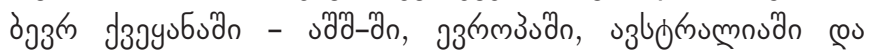

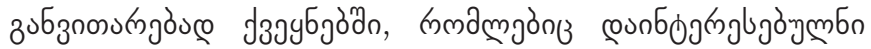

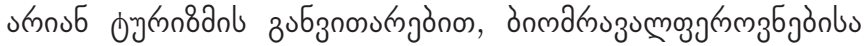

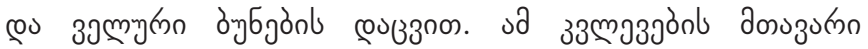
an8uбns nбogm

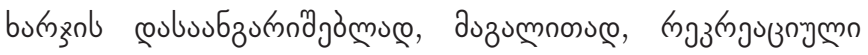

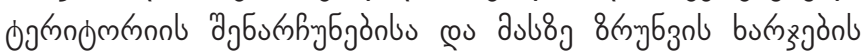

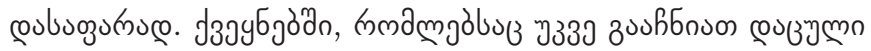

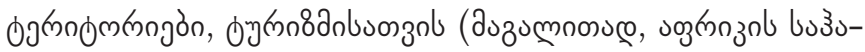

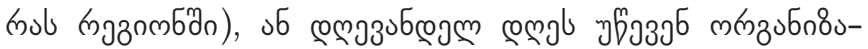

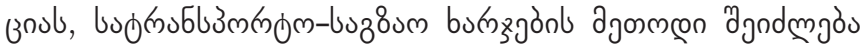

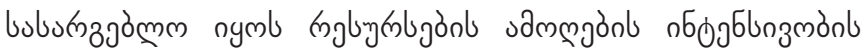

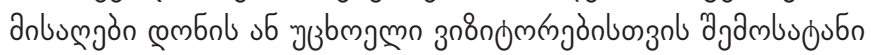

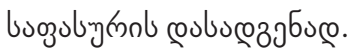

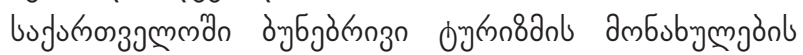

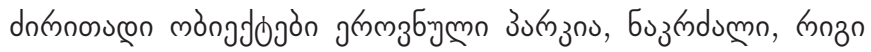

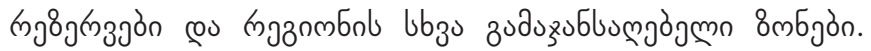

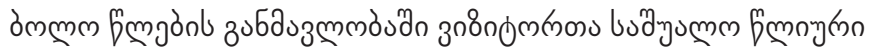

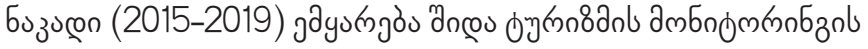
ash 3 бб

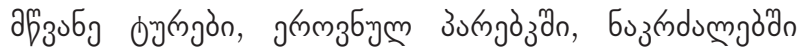

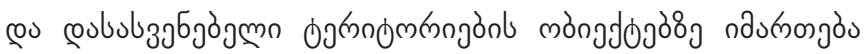

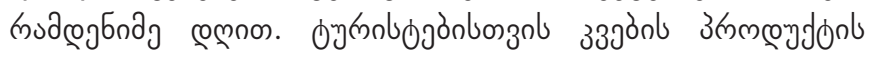

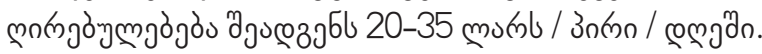

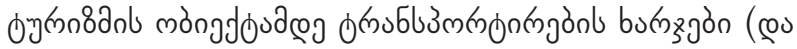

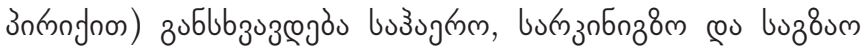

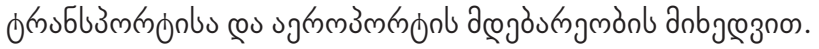

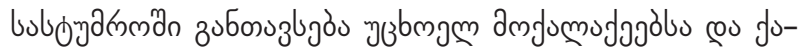

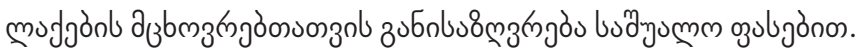

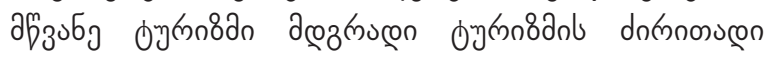

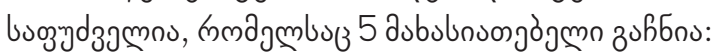

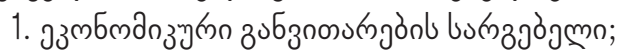

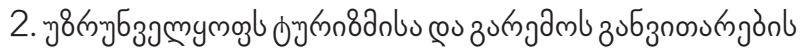

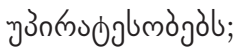

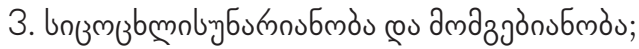

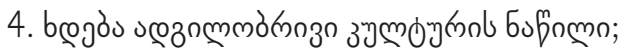




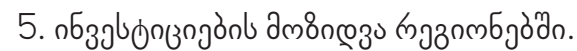

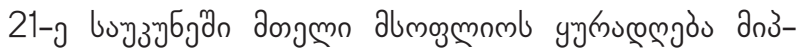

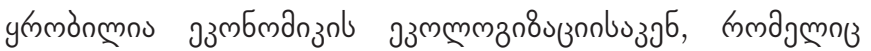

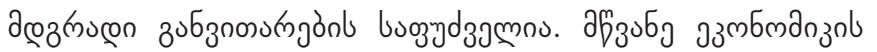

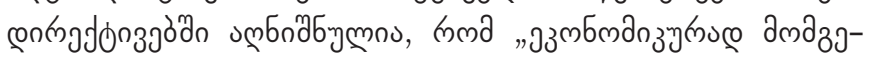

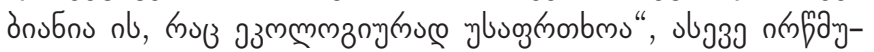

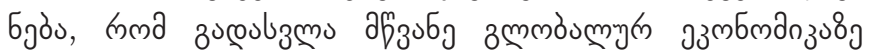

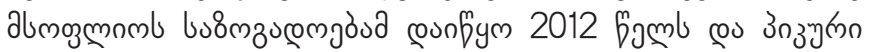
дu

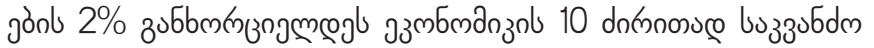

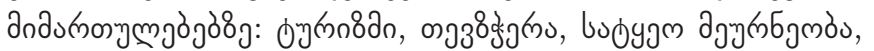

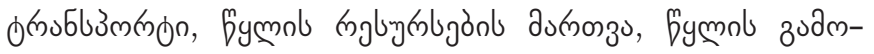

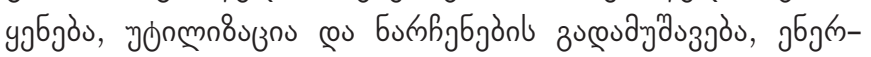

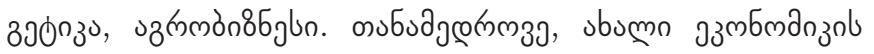

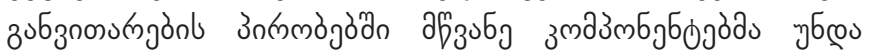

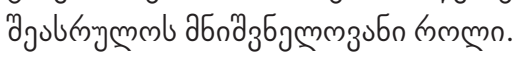

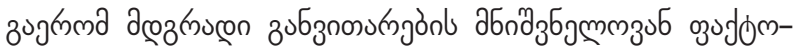

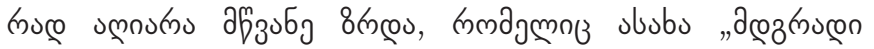

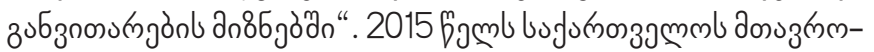

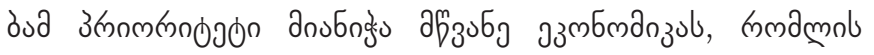

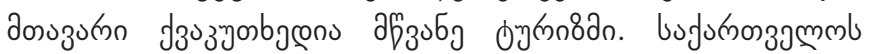

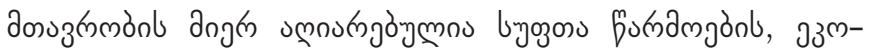

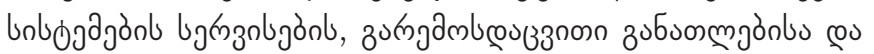

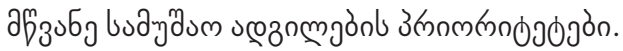

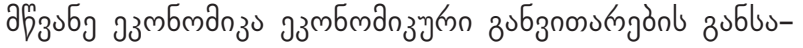

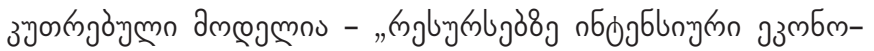

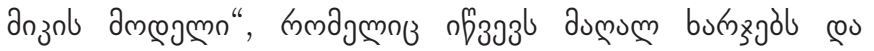

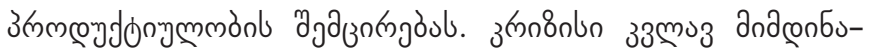

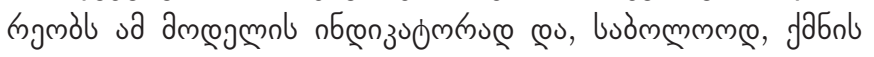

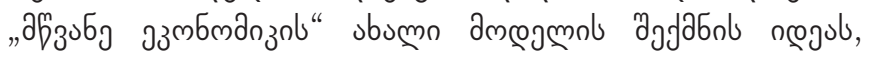

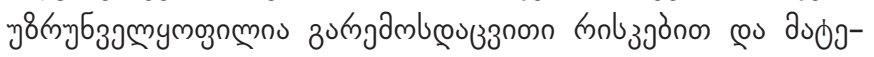

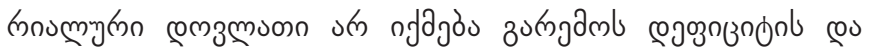

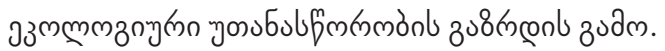

3ง grnmb a

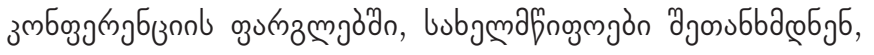

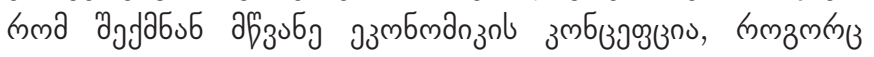
абпазб

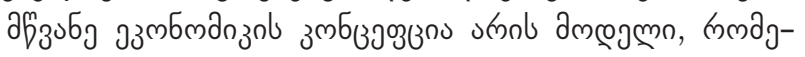

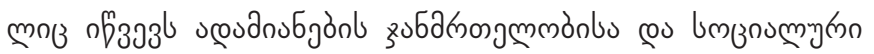

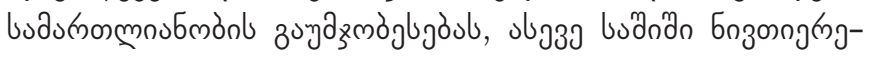

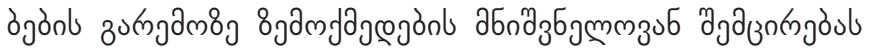

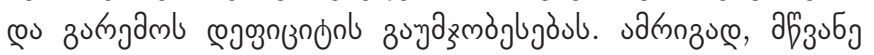

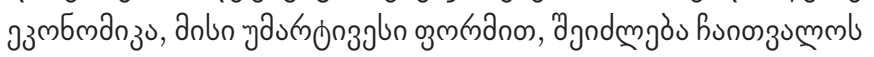

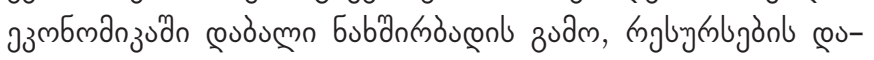

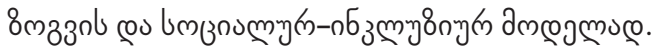

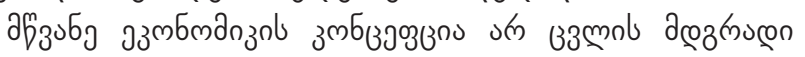

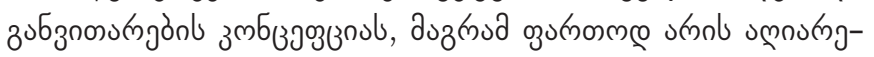

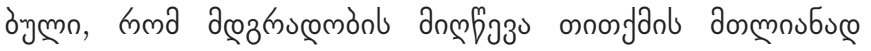

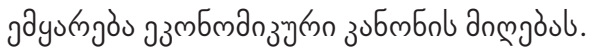

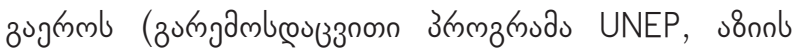

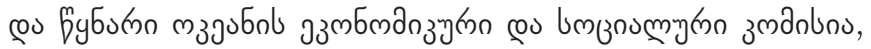

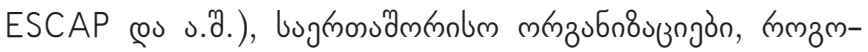

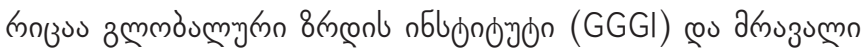

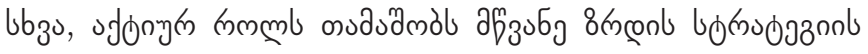

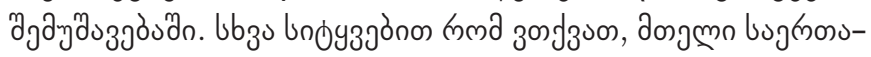

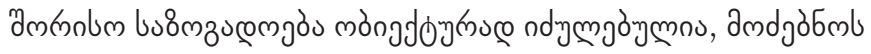

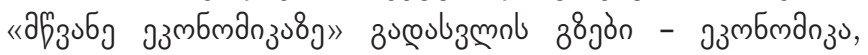

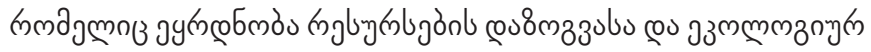

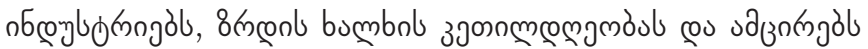

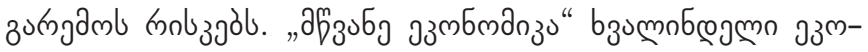

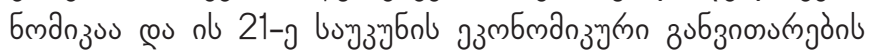
asamdnozjòjgmo dumus.

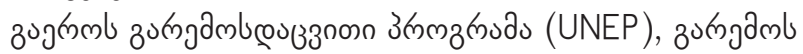

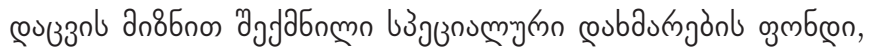

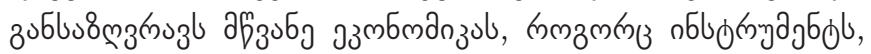

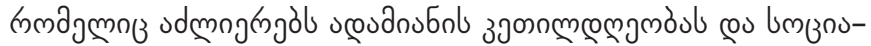

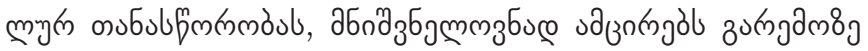

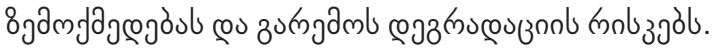

UNEP a

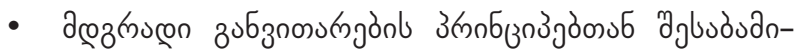
umòs;

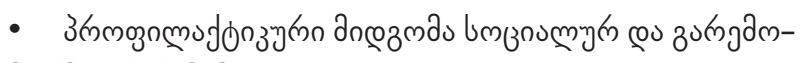

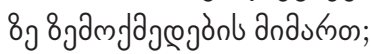

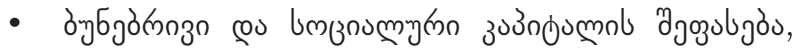

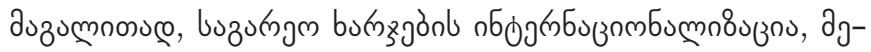

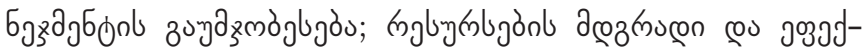

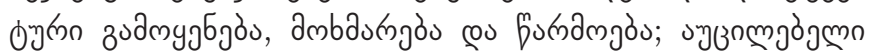

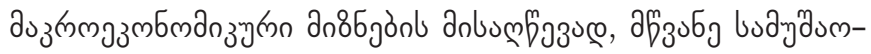

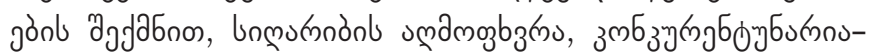

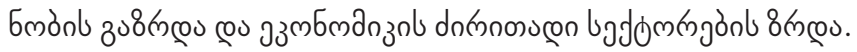

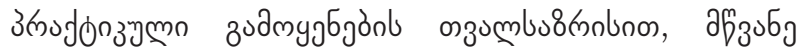
эзмбмдапз

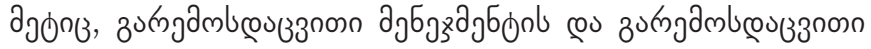

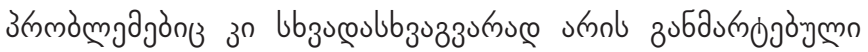

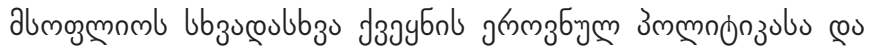

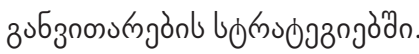

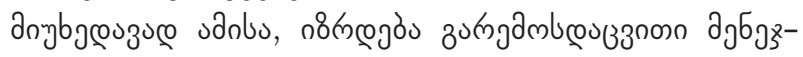

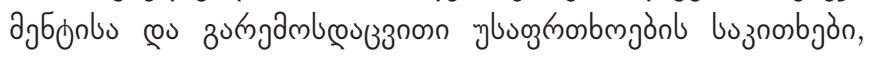

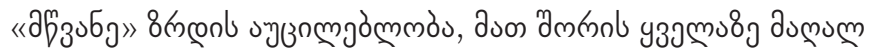

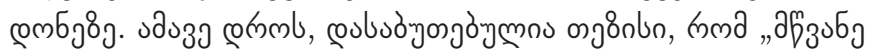

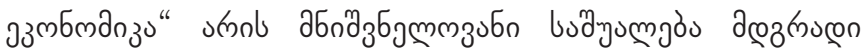

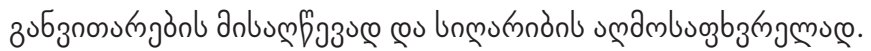

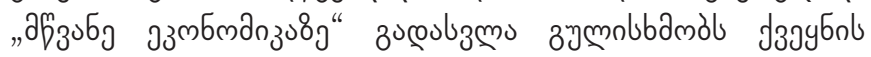

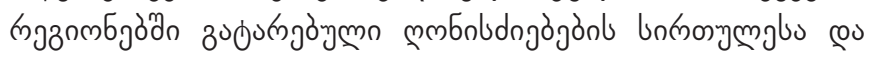

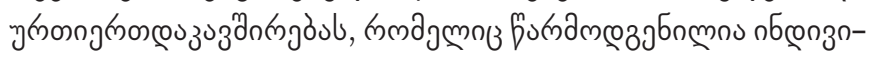

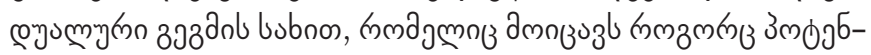

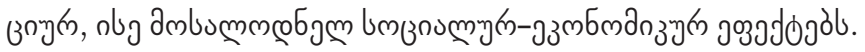

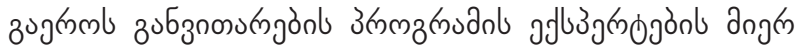

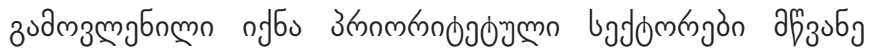

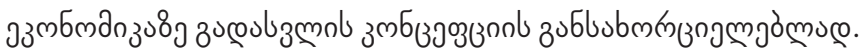




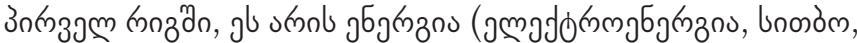

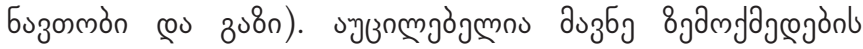

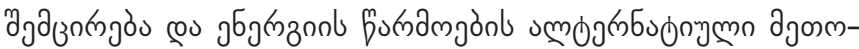

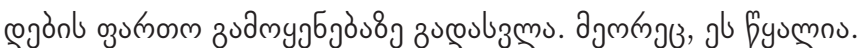

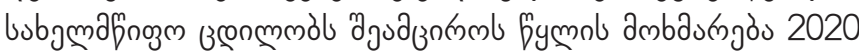

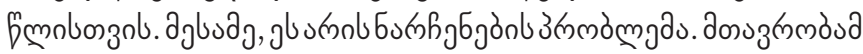

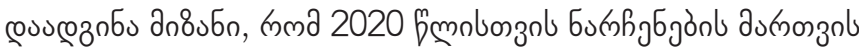

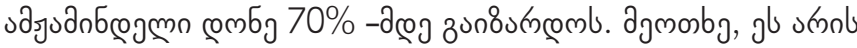

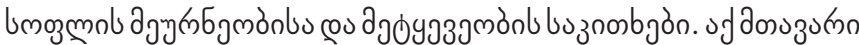

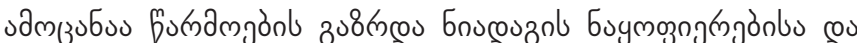

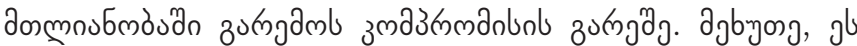
s

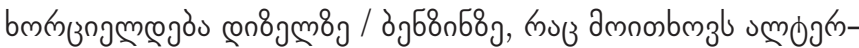

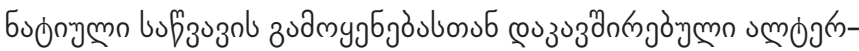

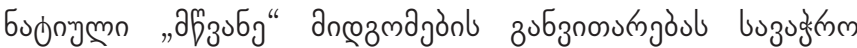

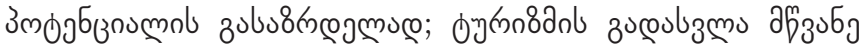

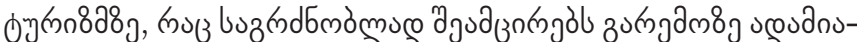

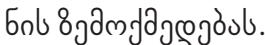

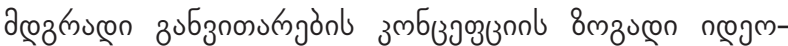

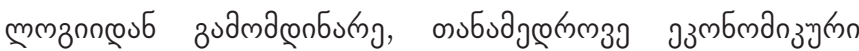

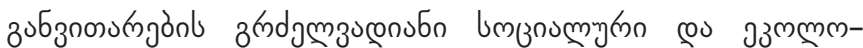

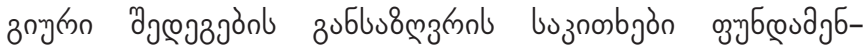

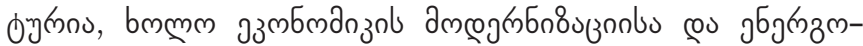

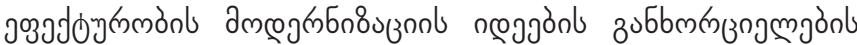

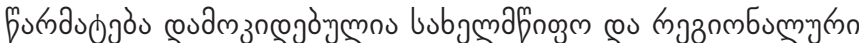

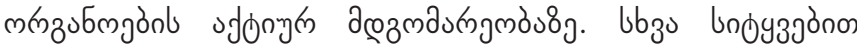

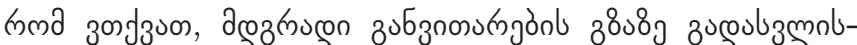

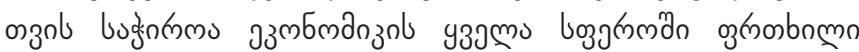

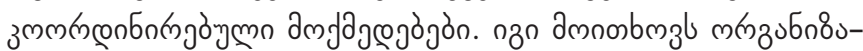

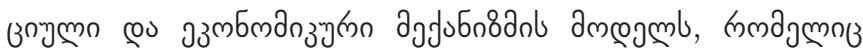

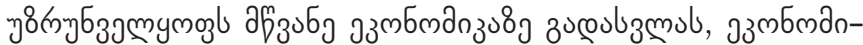

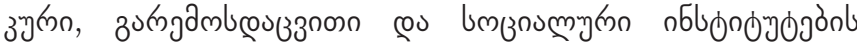

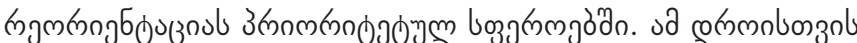

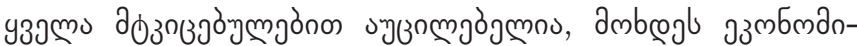

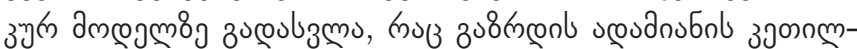

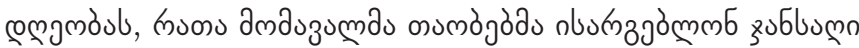
zurgुamon.

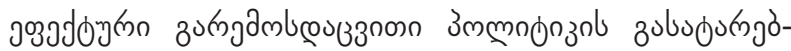

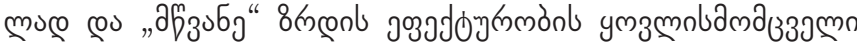

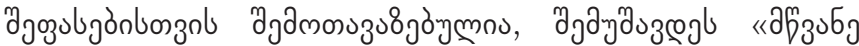

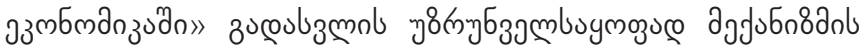

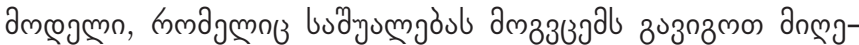

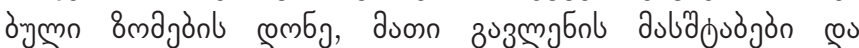

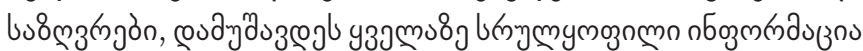

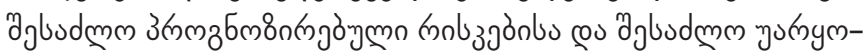

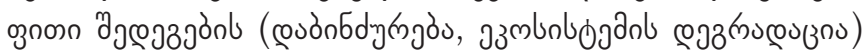
gjbubjo.

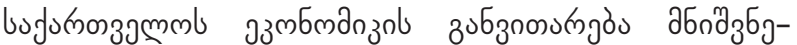

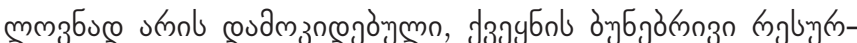
b

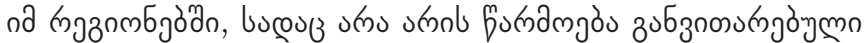

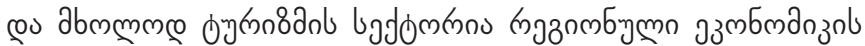
b

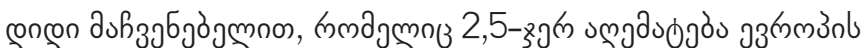

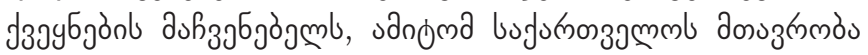

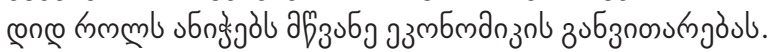

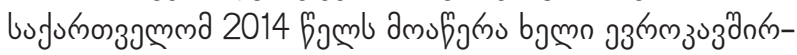

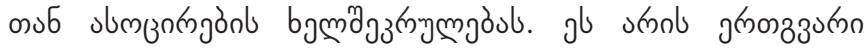

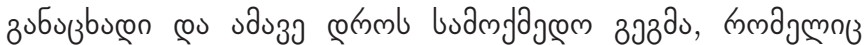

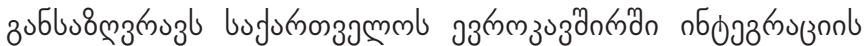

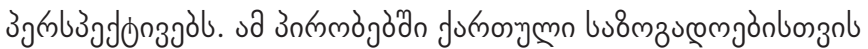

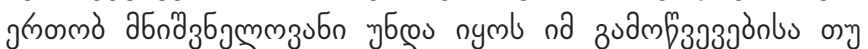

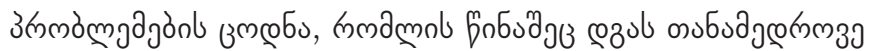

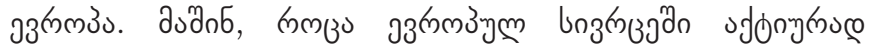

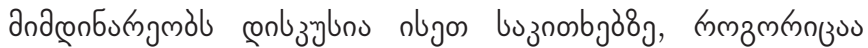

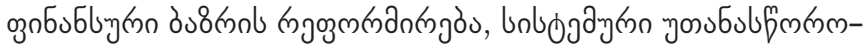

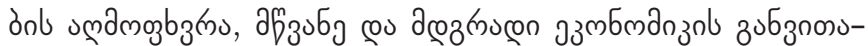

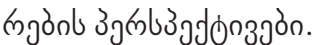

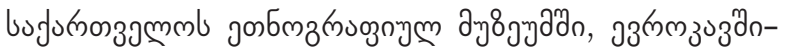

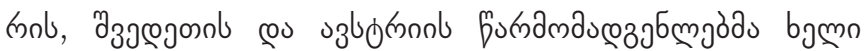

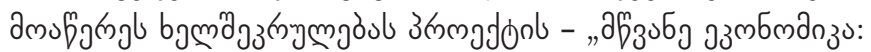

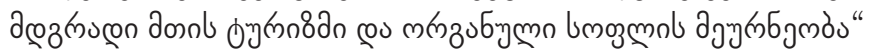

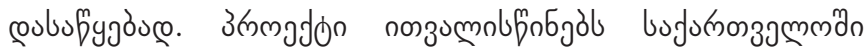

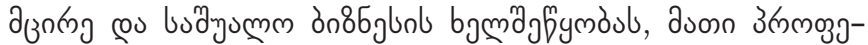

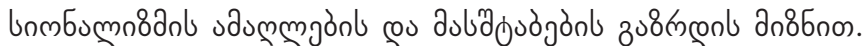

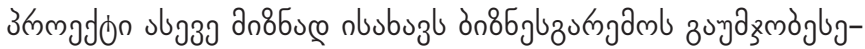

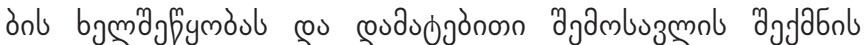

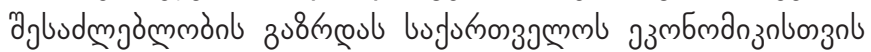

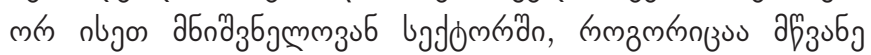

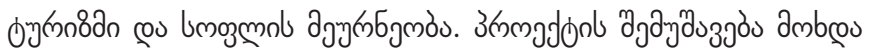

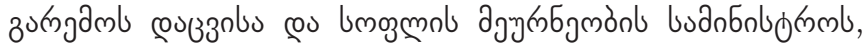

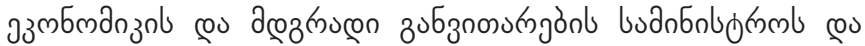

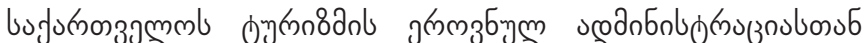

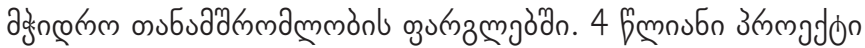

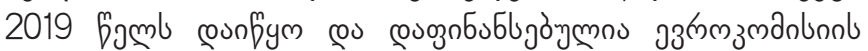

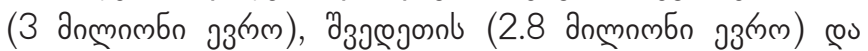

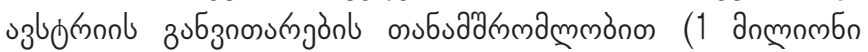

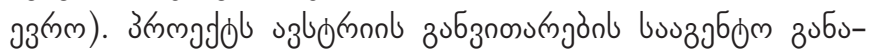

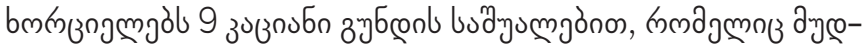

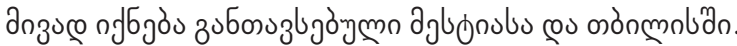

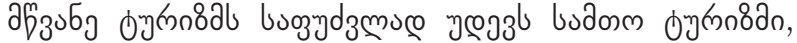

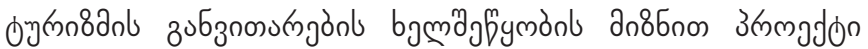

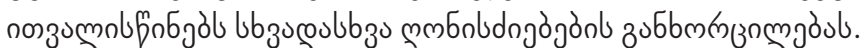

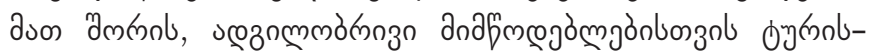
byman b br

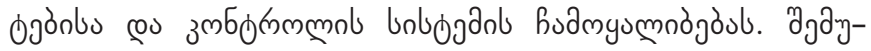

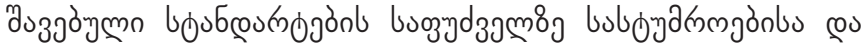

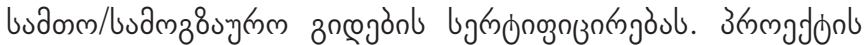

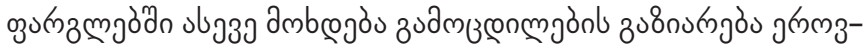

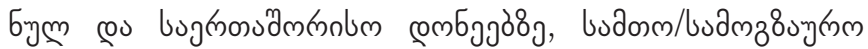




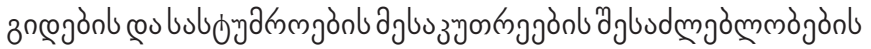

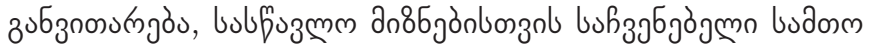
usbonammb ajabs.

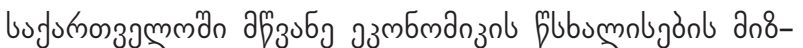

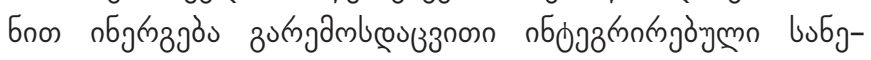

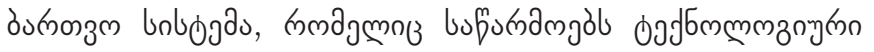

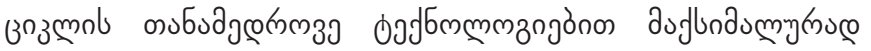

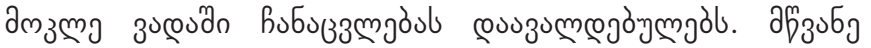

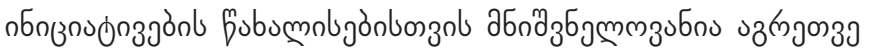

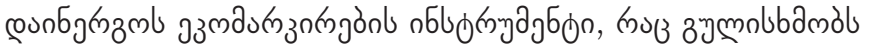

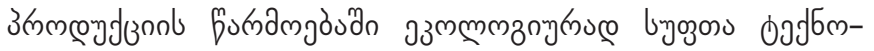

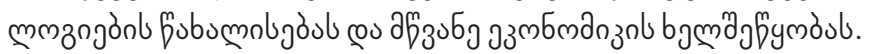

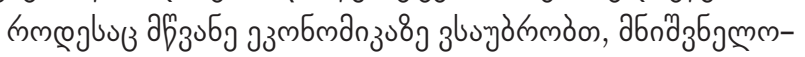

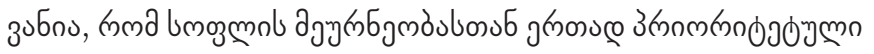

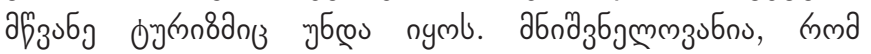

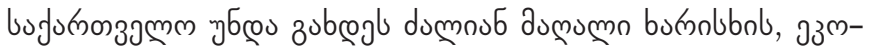

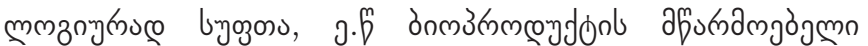
ذзэyง

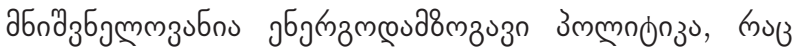

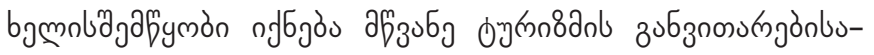

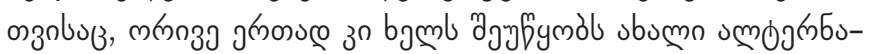

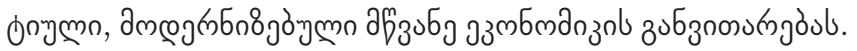

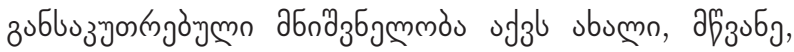

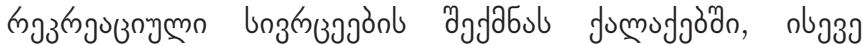

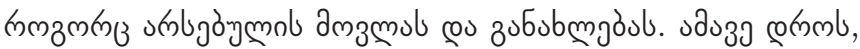

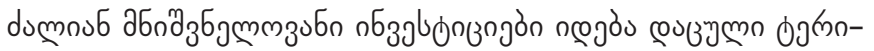

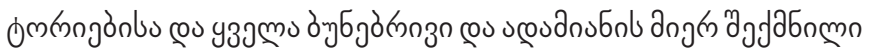

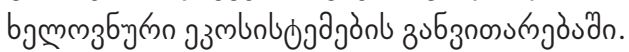

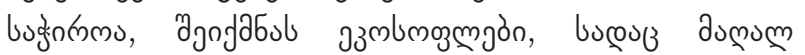

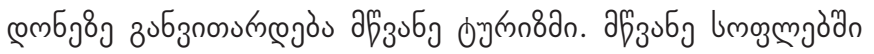

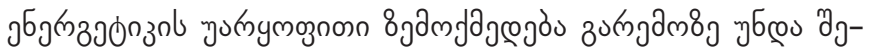

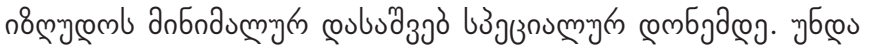

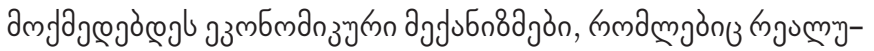

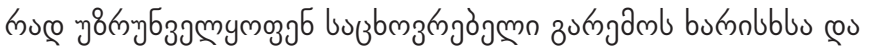

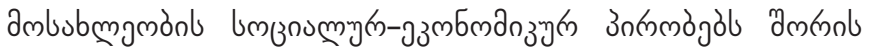

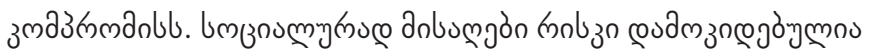

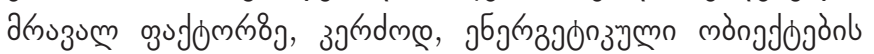

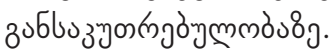

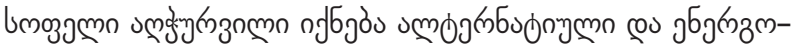

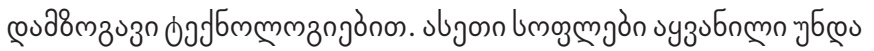
nf

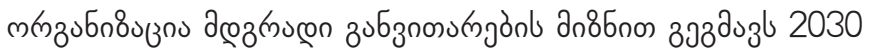

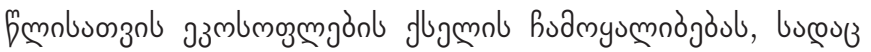

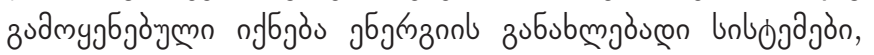

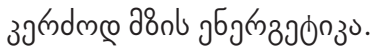

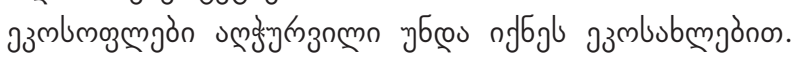

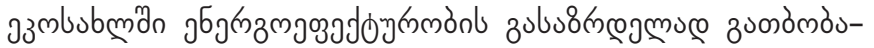

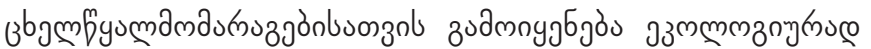

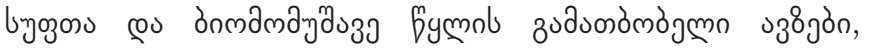

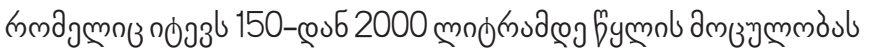

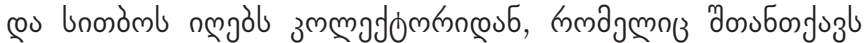

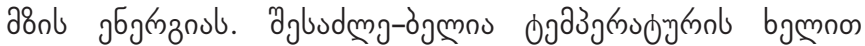

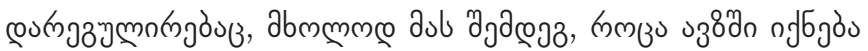

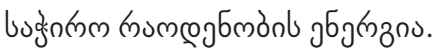

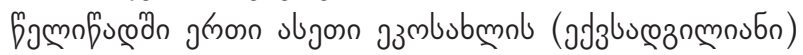

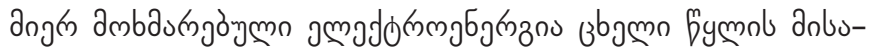

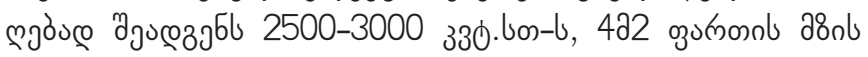

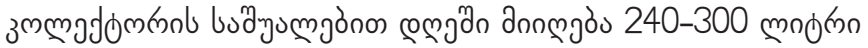

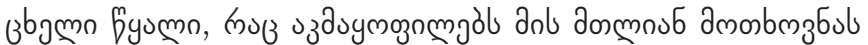

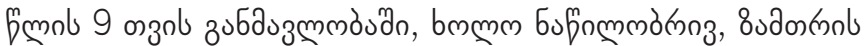

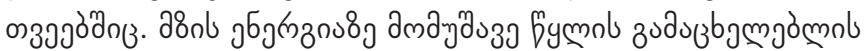

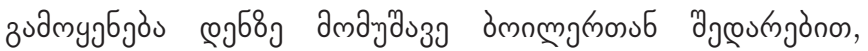

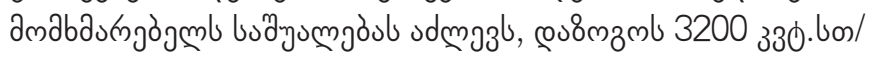

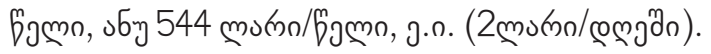

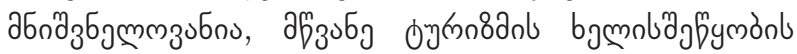

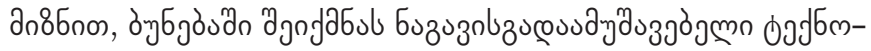

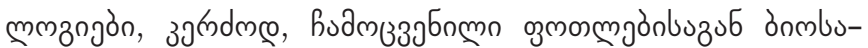

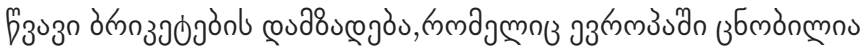
"эз

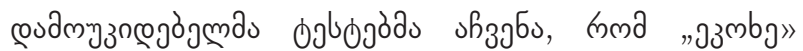

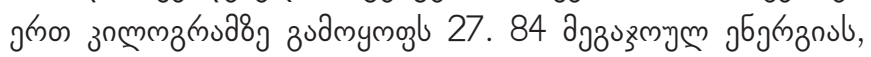

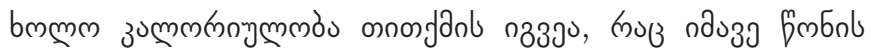

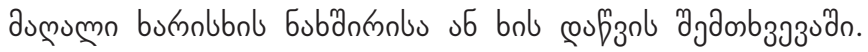

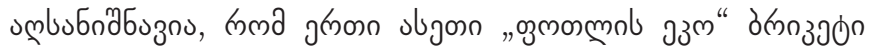

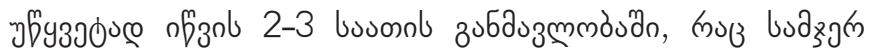

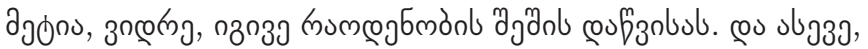

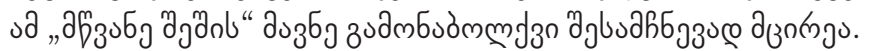

son ا ا

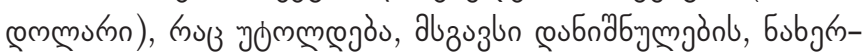

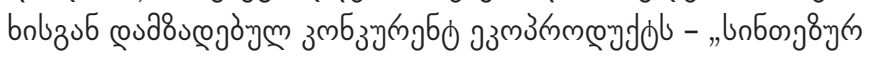

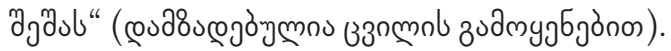

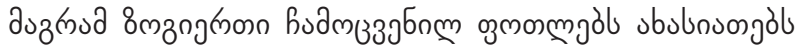

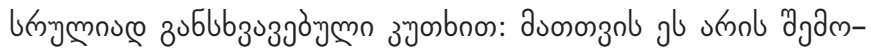

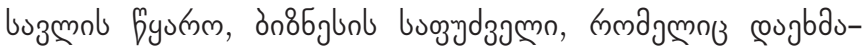

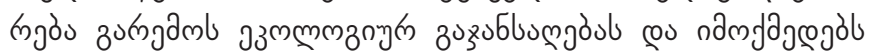

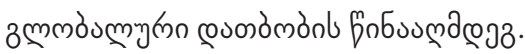

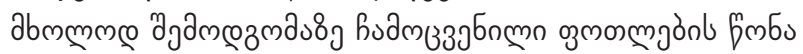

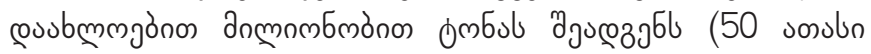

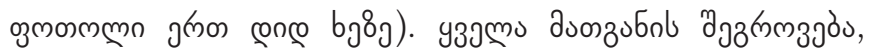

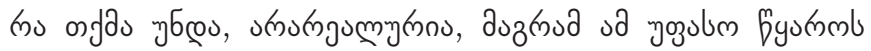

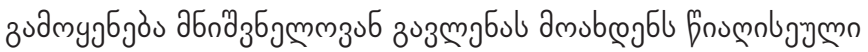

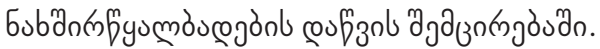

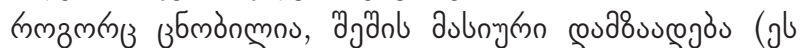

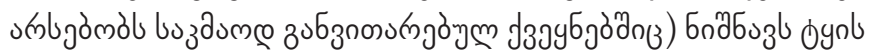

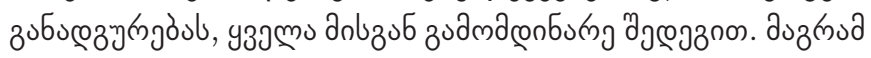

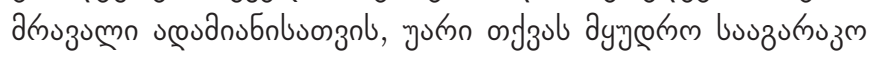

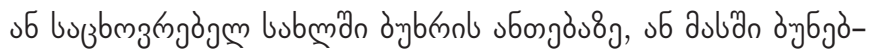

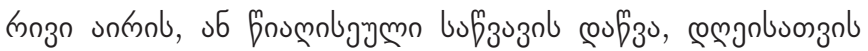

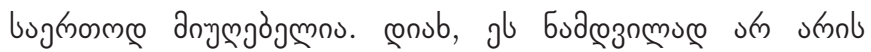
buचzgonglm zuambuzumn. 


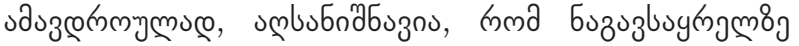

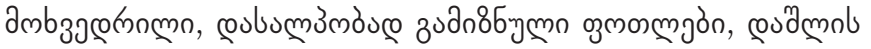

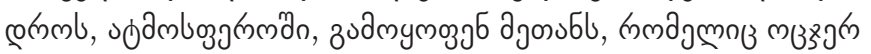

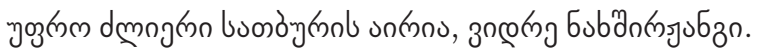

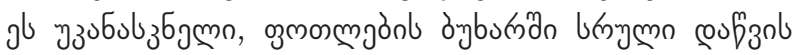

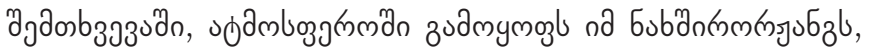

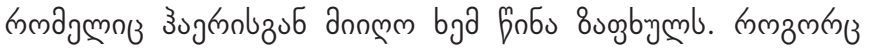

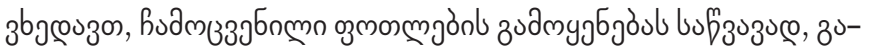
ќ.

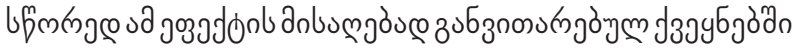

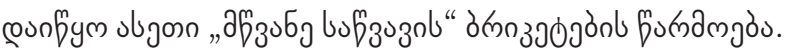

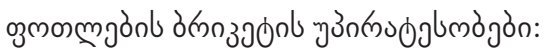

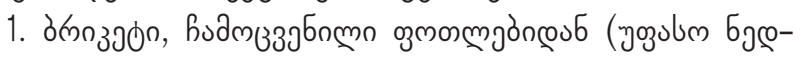
mэymo);

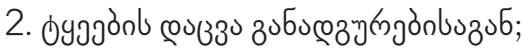

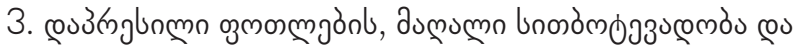

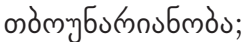

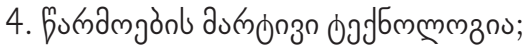

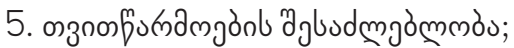

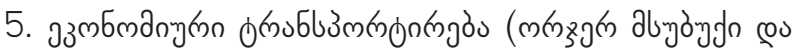

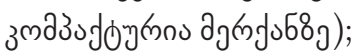

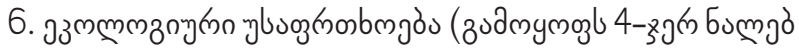

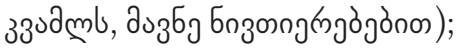

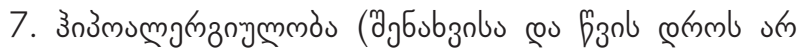

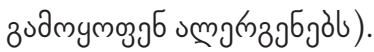

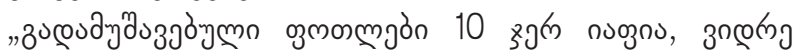

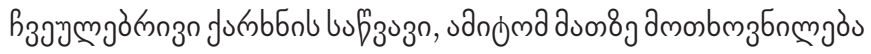

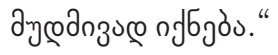

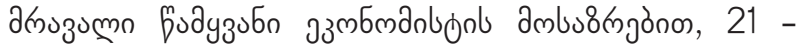

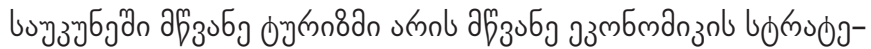

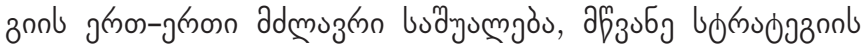
nдзmgagbouzno 3808 j

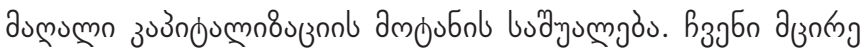

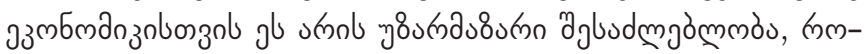

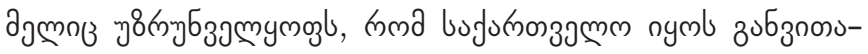
кплау a

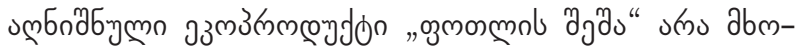

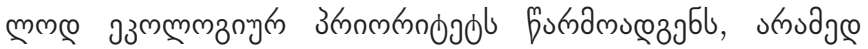

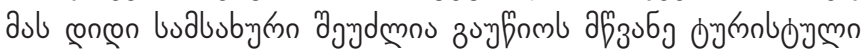

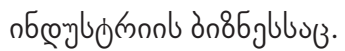

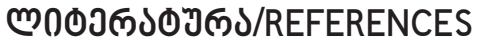

Nolan, E. (2018). Green Events and Green Tourism. London. eBook ISBN9780429445125, Pages196

Susan L. Slocum, Abena Aidoo, Kelly McMahon (2019). The Business of Sustainable Tourism Development and Management.Berlin eBook ISBN9781351031066, 346 pages

Edgell, D., L. (2019). Managing Sustainable Tourism. Warsawa, eBook ISBN9780429318122, 304 pages

Edgell, D. L., Allen, M. D., Smith, G., Swanson, J. (2018). Tourism Policy and Planning. Iondon. eBook ISBN9781351033541, 348 pages

Business planning for specially protected natural areas: methodological guide (2014). Syktyvkar (In Russian)

Bobylev, S.N. (2012). Green economy and modernization. Ecological and economic foundations of sustainable development. Towards sustainable development of Russia. (In Russian).

http://recp.ge/wp-content/uploads/2018/01/Green-economy-newsletter-GE-1.pdf

http://www.mrdi.gov.ge/sites/default/files/1_sakartvelos_socialur-ekonomikuri_ganvitarebis_strategiis_-_ sakartvelo_2020.pdf

http://moe.gov.ge/res/images/file-manager/strategiuli-dokumentebi/strategiebi-gegmebi/2017-2021-.pdf

http://european.ge/mwvane-ekonomikuri-doqtrinistvis-tezisebi/

https://www.facebook.com/bakhtadzemamuka/posts/301440800591996/ 